This is the author's Post-print version (final draft post-refereeing as accepted for publication by the journal). The definitive, peer-reviewed and edited version of this article is published as: Coulter R, van Ham M. \& Feijten P. (2012) Partner (dis)agreement on moving desires and the subsequent moving behaviour of couples. Population, Space and Place 18(1), 16-30.

http://dx.doi.org/10.1002/psp.700

\title{
Partner (dis)agreement on moving desires and the subsequent moving behaviour of couples
}

\author{
Rory Coulter ${ }^{1}$, Maarten van Ham ${ }^{2}$ and Peteke Feijten ${ }^{3}$ \\ ${ }^{1}$ Centre for Housing Research, School of Geography and Geosciences, University of St \\ Andrews, St Andrews, Fife, UK \\ ${ }^{2}$ OTB Research Institute for the Built Environment, Delft University of Technology, \\ Delft, The Netherlands \& University of St Andrews \\ ${ }^{3}$ The Netherlands Institute for Social Research, The Hague, The Netherlands
}

\begin{abstract}
Most studies of residential mobility decision making focus on the housing and neighbourhood satisfaction and pre-move thoughts of individuals. This implicitly assumes that individual evaluations represent the wider household unit. However, if partners in a couple do not share evaluations of dwelling or neighbourhood quality or do not agree on whether moving is (un)desirable, ignoring these disagreements will lead to an inaccurate assessment of the strength of the links between moving desires and actual moves. Although overlooked in studies of residential mobility, partner disagreement plays an important role in the literature on family migration. This study is therefore one of the first to investigate disagreements in moving desires between partners and the subsequent consequences of such disagreements for moving behaviour. Drawing on British Household Panel Survey (BHPS) data and concepts from family migration studies, we find that disagreement about the desirability of moving is most likely where partners do not share perceptions of housing stress. Panel logistic regression models show that the moving desires of both partners interact to affect the moving behaviour of couples. Only $7.6 \%$ of couples move if only the man desires to move, whereas $20.1 \%$ of shared moving desires lead to a subsequent move.
\end{abstract}

Key words: residential mobility; household decision making; moving desires; partner disagreements; satisfaction

\section{INTRODUCTION}

Since the publication of Rossi's Why Families Move in 1955, a large literature seeking to understand the residential mobility process has developed (Dieleman, 2001). There is a tension within this body of work between conceptual models of how households make moving decisions and empirical tests of these models conducted at the individual scale. Conceptual models of residential mobility argue that moving is a household response to housing stress generated by housing disequilibrium, with households seeking to move to 
dwellings and locations which better meet their changing needs and preferences (Clark and Ledwith, 2006). By emphasising the household level, such models implicitly assume that perceptions of housing stress and any resulting moving desires are shared by all members of the household. However, there is considerable evidence that moving desires and evaluations of home and neighbourhood quality are personal thoughts, expressed by individuals in response to the dissatisfaction generated by their own subjective perceptions of housing stress (eg. Landale and Guest, 1985; Lu, 1999). This may explain Ferreira and Taylor's finding (2009) that over $20 \%$ of British couples do not agree about the desirability of moving.

Problematically, existing empirical analyses of the residential mobility process have also neglected the household context within which moving decisions are made. Many studies treat individuals as independent actors, ignoring that people often live and move together in households. Due partly to data constraints, most mobility studies follow only one member of each household, linking their pre-move thoughts to the whole household's subsequent behaviour (see Kan, 1999; Lu, 1999). This approach implicitly assumes that the views of one individual can 'represent' the household unit, or that the desires of one person carry such weight as to largely determine household behaviour.

Interestingly, a related but largely separate literature on long distance family migration does explicitly focus on decision making processes within households (see Cooke, 2008a for an overview). Despite offering conflicting explanations of why households move, both the human capital and gendered migration literatures emphasise that couples and families make migration decisions at the household level (see Cooke, 2008b). It has been well-documented that such decision making does not necessarily involve consensus between the partners; with bargaining, negotiation and trade-offs between the wants of the individual and the net gain to the household all structuring choice processes (Jarvis, 1999; Seavers, 1999). As a consequence some people move against their wishes (tied movers), while others do not move because their partner does not want to (tied stayers). Findings from the family migration literature emphasise that while the household is the site for migration decision making, it is the interaction between individuals within the household context which determines the outcome of the mobility process.

While residential mobility may not involve as great a degree of dislocation and may therefore stimulate fewer disagreements about the desirability of moving, this may be counterbalanced by the increased potential for disagreement produced by conflicting perceptions of housing and neighbourhood quality. Excepting some initial exploration by Buck (2000) and Ferreira and Taylor (2009), very little is known about which couples are more likely to experience moving desire disagreements or whether such disagreements affect subsequent moving behaviour. It seems likely that the desires of both partners interact to condition the subsequent mobility of a couple, with moves less likely to occur if only one partner desires to move than if this desire is shared. Failing to consider the thoughts of both partners may therefore partially explain why many longitudinal studies find that a large proportion of individuals desiring, intending or expecting to move fail to subsequently relocate (eg. Buck, 2000; De Groot et al., 2011; Kan, 1999). It is likely that in a proportion of these cases the person is tied to their current location as their partner does not wish to move.

This study aims to investigate which couples are more likely to disagree about whether moving is desirable and whether such disagreements have consequences for 
subsequent moving behaviour. We analyse the moving propensity of couples using 8 waves of British Household Panel Survey (BHPS) data and panel logistic regression models, taking into account (dis)agreements on evaluations of housing and neighbourhood quality and (dis)agreements on moving desires and expectations.

\section{BACKGROUND}

Studies of geographic mobility have typically identified the motivation for a move using the distance moved as a proxy variable. In this framework, long distance migration events are thought to be mainly motivated by employment opportunities, while short distance residential mobility is usually undertaken to adjust housing consumption (Clark and Huang, 2004). Given that this dichotomy is increasingly being questioned (eg. Boyle et al., 2009; Flowerdew and Al-Hamad, 2004), developing a better understanding of how households make moving decisions requires consideration of both the migration and residential mobility literatures. Insights and concepts from family migration research can be profitably extended to help explain how couples negotiate short distance and non-economically motivated moves.

According to Cooke (2008b), the concept of the family or the household has guided migration research for several decades. The genesis of interest in family migration is often attributed to the classic work by Mincer (1978). In this article, Mincer drew on human capital theory to argue that net household rather than individual gain drives family migration behaviour. For couples this means that individuals may make moves which negatively affect their own labour market position (for instance through reduced earnings or temporary loss of employment), because this loss is counterbalanced by greater gains for the family as a whole. Individuals may also be forced to forgo moving for personal gain, as such a move would incur net costs to the wider family unit (Clark and Davies Withers, 2002). Mincer coined the terms 'tied mover' and 'tied stayer' to describe these situations respectively. Mincer's argument that the household is the level at which migration decision making occurs has informed a vast literature, much of which has sought to explore which partner gains and loses from (im)mobility (Cooke, 2008a; Mulder and Cooke, 2009).

Within this rich literature, most studies share the basic understanding that the household is the appropriate level at which to empirically investigate the outcomes of migration behaviour. Such an approach is supported by qualitative analyses of the household decision making processes preceding a migration event. Bailey et al. (2004) contend that couple households can profitably be considered as a network of socially and geographically 'linked lives'. As partners are bound together into a single family unit, finding a new location which can satisfy the demands of both individuals is difficult (particularly if both wish to be active in the labour market). This forces couples to make moving decisions cooperatively through bargaining and negotiation (Abraham et al., 2010; Hiller and McCaig, 2007). Consistent with the tied mover/stayer framework, many studies find that decision making also involves making trade-offs and individual concessions for the sake of the household (see Jarvis, 1999; Seavers, 1999).

This focus on the household as the appropriate conceptual and empirical unit of analysis is less visible in the residential mobility literature, excepting a number of studies exploring dwelling preferences and housing choice behaviour (see Dieleman, 2001). Conceptual stress-threshold models of residential mobility explain moving 
behaviour as a household adjustment to increases in housing stress. This stress is generated when a household lives in housing disequilibrium, residing in a dwelling and neighbourhood which no longer meets the needs and preferences of the household members (Clark and Ledwith, 2006). Households decide to move in response to rising stress, attempting to relocate to a new dwelling which better satisfies their changing needs, desires and aspirations (Brown and Moore, 1970; Rossi, 1955). Disequilibrium between current and desired housing consumption can occur rapidly, as events in the life careers of household members (such as union formation or dissolution, childbirth or changes in employment status) alter housing needs and preferences (Mulder and Hooimeijer, 1999). Housing stress can also arise more gradually, producing dissatisfaction with the dwelling or neighbourhood before triggering the initiation of the moving process (see Lu, 1999; Speare et al., 1975).

While conceptual models of residential mobility decision making consider the household as the appropriate unit of analysis, empirical tests of these models have often been conducted at the individual level. Thus for example, while the classic studies of Rossi (1955) and Speare et al. (1975) focused conceptually on the mobility of households, their empirical analyses were based around examining the opinions of only one adult individual per household. While more recent studies often recognise the weaknesses and assumptions of such an approach, the limited availability of survey data has ensured that individual level analyses of mobility decision making and subsequent behaviour remain common (eg. De Groot et al., 2011; Kan, 1999; Lu, 1999).

These individual level analyses have yielded valuable insights into the residential mobility process and there is a growing literature documenting how individuals react to increases in housing stress. The initial response to dwelling and/or neighbourhood dissatisfaction generated by stress is usually thought to consist of expressing a desire to move. Such moving desires are relatively unconstrained, as individuals do not necessarily assess the feasibility of moving in detail before expressing a desire to move (De Groot et al., 2011; Van Ham and Feijten, 2008). If the individual perceives that they possess sufficient resources and there are opportunities within the wider housing market to realise their desire, an expectation of moving may be expressed as the commitment to moving increases and alternative dwellings are assessed (Sell and De Jong, 1983). Eventually a move may subsequently occur. This decision making process can be disrupted by unplanned life events, such as losing a job or union dissolution. Such events may force individuals to change their mind about moving or alter the urgency with which a move is required (De Groot et al., 2011). It is therefore important to consider combinations of pre-move thoughts to build a more accurate picture of how moving decisions are made (Coulter et al., forthcoming; Sell and De Jong, 1983).

This study argues that it is conceptually and empirically valuable to enrich this individual level approach with insights from the family migration literature, by considering that individuals within households can disagree about the desirability of moving. It is highly likely that in the context of residential mobility, partners may not share perceptions of housing stress and hence may disagree about whether moving to reduce dissatisfaction is desirable. Barring studies by Buck (2000), Ferreira and Taylor (2009) and Rabe and Taylor (2010), little is currently known about the occurrence or consequences of such disagreements. We might anticipate that individuals with widely differing life careers and hence different needs and priorities may be more likely to 
disagree about whether moving is desirable, as they are less likely to share perceptions of housing stress. We can therefore formulate a hypothesis which states that:

1) Partners are more likely to disagree about whether moving is desirable if they are less similar to one another.

It is likely that disagreements about the desirability of moving are also related to the levels of commitment tying the couple together. Embarking upon major commitments such as marriage, parenthood and homeownership restricts the freedom of the individuals involved, by constraining the future choices they are free to take. As a result, individuals typically only select themselves into such commitments when they perceive a stable, shared future (Feijten, 2005). Given that the highly committed have chosen to restrict their future options and are likely to have been a couple for longer, we might expect such couples to be unlikely to disagree about whether moving is desirable. Less committed couples may feel less pressure to compromise or adjust their desires for the sake of their relationship; thereby making them more likely to disagree about whether moving is desirable. This leads us to hypothesise that:

2) Partners are more likely to disagree about whether moving is desirable if they possess fewer joint commitments.

Disagreements about the desirability of moving may affect the subsequent moving behaviour of couples. Thus the tied mover/stayer concepts developed in the family migration literature may be usefully extended to also conceptualise household moves made over shorter distances and/or for non-economic reasons. The prospect of one partner becoming a 'tied mover' (which refers here to the individual who sacrifices their desire to stay for the sake of their partner) is likely to reduce the propensity for the couple to move, when compared to couples where the partners agree that moving is desirable. If this is the case and there are substantial effects of (dis)agreement on the likelihood of individual desires being realised, this implies that a household level approach is valuable in mobility research (following Boyle et al., 2001). We can therefore formulate two further hypotheses:

3) Couples are least likely to move if neither partner desires to move and are most likely to move if a move is desired by both partners.

4) Couples are less likely to move if only one partner desires to move than if both partners desire to move.

Rabe and Taylor (2010) have previously reported that the moving behaviour of couples was strongly affected by whether the woman (dis)liked the neighbourhood, although the possible mediating effects of moving desires were not considered (see Landale and Guest, 1985). Following this evidence and in light of the large literature on gendered migration, it seems relevant to investigate whether gender affects the likelihood of an individual becoming the tied partner who moves or stays against their wishes. From the migration literature, we can therefore hypothesise that:

5) Couples are more likely to move if only the man desires to move than if only the woman desires to move. 


\section{DATA AND METHODS}

This study uses data from the British Household Panel Survey (BHPS). The BHPS is a panel survey initiated in 1991, when a nationally representative sample of 10,300 individuals from 5,500 UK households were selected and interviewed (Taylor et al., 2010). These individuals have been re-interviewed annually on a wide range of topics, with additional households added to the panel from Scotland, Wales and Northern Ireland in 1999 and 2001. In addition to possessing a large sample surveyed over many time points, the BHPS is ideal for this project for two main reasons. The first key advantage of the BHPS is that it gathers information about moving desires and expectations from all adults living with a sample member. This enables the construction of variables indicating (dis)agreements in moving desires and expectations between partners living in couples. A second advantage of the BHPS is its comparatively low attrition rate (Berthoud, 2000). While movers are known to be more likely to drop out of the sample than non-movers, the BHPS typically records whether individuals have moved even if they were not re-interviewed (Buck, 2000). This enables us to retain these cases in our analyses of actual moving behaviour.

This study makes use of a person-year file based on eight waves of the BHPS covering the years 1998-2006. Earlier waves could not be used as information on moving expectations was not gathered until 1998. Wave 11 (2001) cases were excluded as housing satisfaction information was not gathered during this survey sweep. Given the aims of this paper, the research population consisted of individuals who had an identified and opposite sex 'lawful spouse' or 'live-in partner' in their household. A very small number of person-years where the partners lived in an institution were excluded, as these couples are unlikely to have independent housing careers. Personyears where key household information was missing (such as housing tenure or income) were removed. Cases were also dropped where it was impossible to compute household level similarity or (dis)agreement variables, as only one partner had responded to the relevant survey question. Moving desires were coded using the response to the question 'If you could choose, would you stay here in your present home or would you prefer to move somewhere else?' Similarly, moving expectations were identified from the response to the question 'Do you expect you will move in the coming year?'. A small proportion of respondents replying that they 'did not know' whether they desired or expected to move were treated as having no desire or expectation of moving. This is because these individuals appear not to have given moving much thought. In addition, analysis was restricted to couples that stayed intact between two consecutive waves.

Couples were defined as 'movers' if both changed their address between $t$ and $t+1$ and they remained in the same household and relationship. Likewise, couples were defined as 'stayers' if neither moved and they remained partners. This procedure takes into account that individuals may not change marital status but may change partner between waves (particularly if they cohabit). Longer observation intervals for identifying a move (for example over the subsequent 2 or 3 years) were rejected due to the phrasing of the survey questions, which explicitly obtained the respondent's moving expectations over the next year. In addition, using longer observation windows would ignore that the respondent's expressed desires and expectations may have changed at the intervening waves. If only one partner moved or both partners moved but to different 
households, the couple were assumed to have separated and these person-years were omitted (see Cooke, $2008 \mathrm{~b}$ for a similar sample selection procedure). After transforming the person-year file into a couple-year format, 30,617 couple-years remained, provided by 6,675 couples over an average of 4.6 waves.

The first set of cross-tabulations linked various household level independent variables to the occurrence of disagreements in moving desires between partners. To investigate the effects of disagreements on the subsequent moving behaviour of couples, random effects (panel) logistic regression models were used (Hsiao, 2003). The dependent variable in these models is a binary variable indicating whether the household moved over the subsequent survey year $(0=$ no move, $1=$ move $)$. The control variables in these models contain lagged values, with transition variables measuring the occurrence of life events (such as changes in employment status) between the observation of moving desires at $t$ and moving behaviour at $t+1$. Table 1 provides a summary of all variables used in these analyses. Panel models are valuable as they account for the non-independence of observations, as couple-year cases are nested within couples.

$$
\text { ***Table } 1 \text { about here*** }
$$

\section{RESULTS}

\section{The occurrence of disagreements}

The descriptive results presented in Table 1 and Figure 1 confirm that it is important to consider the pre-move thoughts of both partners in couples. Partners often disagree about whether a move is desired (19.11\% of cases) or expected (4.36\% of cases). Figure 1 shows how partner (dis)agreement on moving desires and the actual mobility rate vary with the age of the older partner in the couple. Disagreements appear to occur fairly consistently across the life course, although younger couples are more likely to disagree than older couples. While total agreement rates remain fairly stable, the composition of this agreement shifts from desiring to move to not desiring to move as age increases. It is important to note that the actual mobility rate is consistently lower than the proportion of couples where one or both partners desire to move (sum of disagree and both desire). This suggests that many people may be unable to act upon their moving desires, or that moving desires are often unattainable and hence abandoned.

$$
* * * \text { Figure } 1 \text { about here*** }
$$

Table 2 presents data on the associations between partner similarity and (dis)agreement on moving desires. The results provide only weak support for the idea that partners who are demographically and socioeconomically more similar to one another are less likely to disagree about whether moving is desirable. The age gap separating partners appears unrelated to the propensity for partners to disagree about whether moving is desirable, although couples separated by the largest age gaps are slightly more likely to disagree. Ethnically mixed couples are more likely to disagree than ethnically homogenous couples, despite the idea that only more committed individuals are willing to enter into such unions. A gap in educational levels between partners seems unrelated to 
(dis)agreement on moving desires. Both dual and single earner couples are more likely to disagree than couples where neither partner is employed.

**Table 2 about here***

The results in the lower section of Table 2 provide preliminary support for the contention that disagreement about whether moving is desirable is more likely when partners also disagree about the quality of their dwelling or neighbourhood. Disagreements are most likely to occur if the partners already disagree about whether they are satisfied with their dwelling or dislike their neighbourhood. Further analysis (not shown) reveals that it is almost always the partner who is unhappy with their dwelling or neighbourhood who desires to move. This suggests that individual moving desires are stimulated by personal subjective evaluations of dwelling and neighbourhood conditions (Landale and Guest, 1985). This interpretation is further supported by the strong links between shared negative evaluations (particularly of the neighbourhood) and shared desires to move: more than $96 \%$ of couples who agree on disliking the neighbourhood also share a desire to move. Couples who disagree about their housing or neighbourhood conditions also often agree that moving is desirable. This suggests that people often take their partner's happiness with their current location into account when expressing their own moving desires. This would not be visible in an individual level study.

$* * *$ Table 3 about here***

Table 3 presents descriptive results linking the level of shared commitments to the relationship to moving desire (dis)agreements. There is somewhat mixed support for the commitment hypothesis, which proposed that possessing fewer joint commitments is associated with a greater propensity for partners to disagree about the desirability of moving. Disagreements are more likely among cohabiters than married couples, with cohabiters also much more likely to agree that moving is desirable. This may indicate that individuals select into marriage when they foresee that a shared future living arrangement is feasible, typically as relationship duration and stability increase. Disagreements also appear to be more common for couples with children, with the incidence of disagreement generally increasing with the age of the children (see also Ferreira and Taylor, 2009). This suggests that although families with children are fairly immobile, it is common for one or both partners to still desire to move. There is also some evidence that tenure commitments are linked to desire disagreements. Highly committed homeowning couples disagree in $18.55 \%$ of cases, whereas disagreements are slightly more common amongst renting couples (just over $21 \%$ ). Again this suggests that individuals often enter committed states only when they perceive that the needs of both partners can be met through residence at a single location.

Overall we have found little convincing evidence that levels of partner similarity are associated with moving desire disagreements. We did find that disagreements are most likely to occur when the partners disagree about the quality of their dwelling or neighbourhood. These findings provide initial support for conceptual models of residential mobility decision making (see $\mathrm{Lu}, 1999$ ). There is also some support for hypothesis 2, suggesting that greater levels of commitment are associated with a reduced propensity to disagree about whether moving is desirable. 


\section{Desire disagreements and actual moving behaviour}

Table 4 contains descriptive results testing the third and fourth hypotheses. The results indicate that taking the moving desires of both partners into account more accurately predicts whether couples subsequently move. The upper section of Table 4 links the desires of only the male partner to the couple's moving behaviour over the next year. Ignoring the views of the female partner, these results show that $15.90 \%$ of couples where the male desires to move also actually move.

The lower section of the table reveals however that the likelihood of the male partner's desire to move being realised is heavily dependent upon the views of his partner. If only the male partner desires to move, then a move occurs in $7.57 \%$ of cases. If both partners desire to move then a move occurs in over $20 \%$ of cases. These findings support the hypothesis that moving desires are most likely to be realised if shared by both partners. This demonstrates that linking only one partner's desires to the actual moving behaviour of the couple leads to inaccurate estimates of how strongly desires are associated with actual moves. Shared moving desires are much more likely to be realised than desires which are not shared.

$$
* * * \text { Table } 4 \text { about here*** }
$$

Table 5 contains the results from five panel logistic regression models estimating the likelihood of couples making joint moves. These models enable robust hypothesis testing, by controlling for the effects of background characteristics known to affect mobility. Our main interest is in how partner (dis)agreements in evaluations of housing and/or neighbourhood quality, moving desires and moving expectations, affect the moving propensity of couples. It is possible that interview conditions may have affected our measurements of (dis)agreements. It is likely that disagreements are less likely to be expressed if both partners are interviewed together. Further analysis revealed that partners are somewhat more likely to disagree if they completed the relevant section of the interview separately than if they were interviewed together. As partners were not interviewed separately in approximately $50 \%$ of cases, we may undercount disagreements in our analyses. To ensure that our results are robust, the models were rerun with a variable indicating the interview conditions included as an extra control. The model results were almost identical to the models without this control variable (not shown).

Model 1 includes only housing dissatisfaction and neighbourhood assessments as independent variables. The model shows that couples are more likely to move if one or especially both partners are dissatisfied with their dwelling or dislike their neighbourhood. Consistent with Rabe and Taylor's (2010) findings, moves are more likely to occur if only the woman dislikes the neighbourhood than if only the man dislikes the neighbourhood.

These parameters remain strong and significant when a range of control variables (but without moving desires and expectations) are added in Model 2. In general the control variables have the effects anticipated from the literature, apart from the negative coefficient of the cohabitation dummy (although this is not significant). The propensity to move decreases with age, and couples with children are less likely to move than those without (particularly if the children are school age or older). Changes 
in the number of children in the household do not appear significantly linked to mobility. High levels of education are associated with a higher probability to move, while single and particularly dual earner couples are less likely to move than couples where neither partner is employed. Interestingly, reductions in the number of people in employment are also associated with moving. This may be due to moves related to retirement. With higher levels of income the likelihood of moving increases. Private renters are more likely to move than those in other housing tenures, while room stress is also associated with a greater propensity to move. The longer people stayed in their current dwelling, the less likely they are to move. Further analyses (not shown here) demonstrate that there is little evidence of any significant regional or period effects on moving behaviour.

$* * *$ Table 5 about here***

Model 3 only includes the moving desires and expectations of both partners. The results support both hypotheses 3 and 4. Desiring to move is associated with a greater propensity to actually move, particularly if this desire is shared between partners. Shared moving expectations are very strongly linked to mobility, although moves are also likely if only expected by one partner (especially if the woman expects to move). The effects of moving desires and expectations remain stable when control variables are included in Model 4. Most of the control variable parameters are similar to those in Model 2, although there are some minor changes in significance levels (for instance education level becomes insignificant). Model 4 fits the data much better than Model 2, as shown by the considerably lower log likelihood value in Model 4. This suggests that desires and expectations are more strongly linked to actual moves than evaluations of dwelling and neighbourhood conditions.

Finally, Model 5 contains all variables included in the previous models. Most of the control variables have similar effects to those estimated in the previous models. The most important finding is that some of the effects of housing satisfaction and all of the effects of disliking the neighbourhood become insignificant when desires and expectations are included in the same model. This indicates that subjective evaluations of dwelling and neighbourhood conditions are associated with moving desires and expectations, with these desires and expectations in turn conditioning the propensity to move (Lee et al., 1994; Rossi, 1955). Rabe and Taylor (2010) have previously reported that whether the female partner dislikes the neighbourhood has a particularly strong effect on whether the household subsequently moves. While this is correct, our results demonstrate that this is also partially dependent on how disliking the neighbourhood affects the moving desires and expectations of both partners. Interestingly, after also controlling for moving desires and expectations, couples remain significantly more likely to move if only one partner is dissatisfied with their dwelling than if both are satisfied. This suggests that housing dissatisfaction can in some circumstances have an independent effect on mobility behaviour.

The moving desire parameters continue to support the hypotheses. Moves are more likely to occur if desired by one partner than if neither partner desires to move, although shared desires most closely predict subsequent moves. In support of hypothesis 5 we find evidence of a gender effect, as men are more likely than women to realise their moving desires if they are unsupported by their partner. However, women appear to be better in predicting a move then men (see parameters for moving 
expectations). Again, this slightly nuances Rabe and Taylor's findings (2010), as it is men who are more successful than women in translating a moving desire into an actual move.

Overall, the modelling results demonstrate the value of conducting analysis at the household level, taking into account the views of both partners. This study showed that it is important to consider the satisfaction and pre-move thoughts of both partners, as the impacts these factors have on actual mobility differs depending upon whether they are shared or held by only one partner. The results also support conceptual models of residential mobility, as dissatisfaction stimulates moving desires and expectations, which in turn affect actual moving behaviour (see Lu, 1999).

\section{CONCLUSIONS}

In contrast to the family migration literature, residential mobility studies have often neglected the importance of the household as the site for mobility decision making. In the residential mobility literature, conceptual models of decision making have tended to view households as unified social units which move in response to housing stress. Empirical tests of these models have often taken the views of only one person as the determinant of the subsequent moving behaviour of the household as a whole. These conceptual and empirical approaches neglect the complexity of decision making within couple and family households, where the decision about whether or not to relocate is likely to involve both partners (Dieleman, 2001). As individual perceptions of housing stress and dissatisfaction are known to motivate mobility, partners may not always agree that moving is desirable.

The first aim of this paper was therefore to assess which couples are more likely to disagree about the desirability of moving. We find that the degree of life course similarity between the partners is only weakly predictive of disagreement, although there is some evidence that joint commitments such as homeownership are associated with a slightly lower propensity for partners to disagree. In contrast, couples reporting differing perceptions of housing stress are much more likely to disagree about whether moving is desirable. Objective household composition therefore seems of considerably less significance than individual perceptions of housing stress as a predictor of disagreement. Interestingly, couples are likely to agree that moving is desirable even when only one partner is unhappy with their dwelling or neighbourhood conditions. This indicates that people are willing to consider moving for the sake of their partner. These findings demonstrate that it is important to think of households as collections of linked lives (Bailey et al., 2004), recognising that individual sacrifice is often necessary to build household consensus.

These findings led us to explore whether disagreements between partners over whether moving is desirable has impacts for the subsequent moving behaviour of households. Given the one-year spacing of BHPS observations, it is possible that the moving desires of one or both partners changed without our knowledge in the interval between expressing their desires at time point $t$ and the observation of their actual moving behaviour at $t+1$. Nevertheless, the results clearly demonstrate that an individual desire to move is much more likely to be realised if shared by both partners. Although recent research shows that housing and neighbourhood dissatisfaction increases the propensity for individuals and households to make residential moves (eg. 
Diaz-Serrano and Stoyanova, 2010; Rabe and Taylor, 2010), this effect appears to be mediated by moving desires and expectations (see Landale and Guest, 1985; Lee et al., 1994). After controlling for satisfaction we also find some evidence of a gender effect, as men are more likely to act upon their desires in the event of a disagreement than women. This finding suggests the value of extending the tied mover/stayer framework into studies of short distance and non-economically driven mobility. The prospect of one partner becoming a tied mover dampens household mobility, while women are more likely than men to fail to realise their desires in the event of a disagreement.

The findings of this study have implications for the development of residential mobility theory and future empirical research. The results clearly show that only taking the views of one partner into consideration when analysing the mobility behaviour of couples biases the outcomes. Partners can disagree on housing and neighbourhood (dis)satisfaction and moving desires, and the relative weight of each partner's views influences subsequent moving behaviour. A household level approach where the views of both partners are taken into account enables us to model more accurately who realises their moving desires and expectations, by treating the views of the partner as further enabling or constraining factors. The existence and behavioural consequences of disagreements are also important for our understanding of housing disequilibrium and household composition. While households may appear to experience equilibrium between their housing supply and consumption, this may only be possible because individuals within the household are prepared to remain in a state of personal disequilibrium as tied movers or stayers. This may have impacts for household composition, potentially undermining partnership stability or contributing to long term decreases in life satisfaction and wellbeing for the tied partner (see Ferreira and Taylor, 2009). This study suggests that considering the housing satisfaction and prior moving desires of both partners in couples allows us to better understand why households move or remain in place.

\section{DISCLAIMER}

The data used in this study were made available through the ESRC Data Archive. The data were originally collected by the ESRC Research Centre on Micro-Social Change at the University of Essex (now incorporated within the Institute for Social and Economic Research). Neither the original collectors of the data nor the Archive bear any responsibility for the analyses or interpretations presented here.

\section{ACKNOWLEDGEMENTS}

Maarten van Ham contributed to this study while working at the Centre for Housing Research, University of St Andrews. Peteke Feijten contributed to the paper while working at the Longitudinal Studies Centre - Scotland, University of St Andrews. The authors would like to thank the two anonymous referees for their valuable comments on the earlier version of this paper. 


\section{REFERENCES}

Abraham M, Auspurg K, Hinz T. 2010. Migration decisions within dual-earner partnerships: a test of bargaining theory. Journal of Marriage and Family 72: 876-892. DOI:10.1111/j.1741-3737.2010.00736.x.

Bailey AJ, Blake MK, Cooke TJ. 2004. Migration, care, and the linked lives of dualearner households. Environment and Planning A 36: 1617-1632. DOI:10.1068/a36198.

Berthoud R. 2000. Introduction: the dynamics of social change. In Seven Years in the Lives of British Families, Berthoud R, Gershuny J (eds.); Policy Press: Bristol; 1-20.

Boyle P, Feng Z, Gayle V. 2009. A new look at family migration and women's employment status. Journal of Marriage and Family 71: 417-431. DOI:10.1111/j.17413737.2009.00608.x.

Boyle P, Cooke T, Halfacree K, Smith D. 2001. A cross-national comparison of the impact of family migration on women's employment status. Demography 38: 201-213. DOI:10.1353/dem.2001.0012.

Brown LA, Moore EG. 1970. The intra-urban migration process: a perspective. Geografiska Annaler. Series B, Human Geography 52: 1-13.

Buck N. 2000. Using panel surveys to study migration and residential mobility. In Researching Social and Economic Change: The Uses of Household Panel Studies. Rose D (eds.); Routledge: London; 250-272.

Clark WAV, Ledwith V. 2006. Mobility, housing stress, and neighborhood contexts: evidence from Los Angeles. Environment and Planning A 38: 1077-1093. DOI:10.1068/a37254.

Clark WAV, Huang Y. 2004. Linking migration and mobility: Individual and contextual effects in housing markets in the UK. Regional Studies 38: 617 - 628. DOI:10.1080/003434042000240932.

Clark, WAV, Davies Withers S. 2002. Disentangling the interaction of migration, mobility, and labor-force participation. Environment and Planning A 34: 923-945. DOI:10.1068/a34216

Cooke TJ. 2008a. Migration in a family way. Population, Space and Place 14: 255-265. DOI:10.1002/psp.500.

Cooke TJ. 2008b. Gender role beliefs and family migration. Population, Space and Place 14: 163-175. DOI:10.1002/psp.485.

Coulter R, van Ham M, Feijten P. Forthcoming. A longitudinal analysis of moving desires, expectations and actual moving behaviour. Environment and Planning A 
De Groot C, Mulder CH, Das M, Manting D. 2011. Life events and the gap between intention to move and actual mobility. Environment and Planning A 43: 40-66. DOI:10.1068/a4318.

Diaz-Serrano L, Stoyanova AP. 2010. Mobility and housing satisfaction: an empirical analysis for 12 EU countries. Journal of Economic Geography 10: 661-683.

DOI:10.1093/jeg/lbp045.

Dieleman FM. 2001. Modelling residential mobility: a review of recent trends in research. Journal of Housing and the Built Environment 16: 249-265.

DOI:10.1023/A:1012515709292.

Feijten P. 2005. Life Events and the Housing Career: A Retrospective Analysis of Timed Effects. Eburon: Delft.

Ferreira P, Taylor M. 2009. Residential mobility, mobility preferences and psychological health. In Changing Relationships, Brynin M, Ermisch J (eds.); Routledge: Oxford; 161-179.

Flowerdew R, Al-Hamad A. 2004. The relationship between marriage, divorce and migration in a British data set. Journal of Ethnic and Migration Studies 30: 339-351.

Hiller HH, McCaig KS. 2007. Reassessing the role of partnered women in migration decision-making and migration outcomes. Journal of Social and Personal Relationships 24: 457-472. DOI:10.1177/0265407507077233.

Hsiao C. 2003. Analysis of Panel Data (Second Edition). Cambridge University Press: Cambridge.

Jarvis H. 1999. The tangled webs we weave: household strategies to co-ordinate home and work. Work, Employment \& Society 13: 225-247.

DOI:10.1177/09500179922117926.

Kan K. 1999. Expected and unexpected residential mobility. Journal of Urban Economics 45: 72-96. DOI:10.1006/juec.1998.2082.

Landale NS, Guest AM. 1985. Constraints, satisfaction and residential mobility: Speare's model reconsidered. Demography 22: 199-222.

Lee BA, Oropesa RS, Kanan JW. 1994. Neighborhood context and residential mobility. Demography 31: 249-270.

Lu M. 1999. Do people move when they say they will? Inconsistencies in individual migration behavior. Population \& Environment 20: 467-488.

DOI:10.1023/A:1023365119874.

Mincer J. 1978. Family migration decisions. Journal of Political Economy 86: 749-773. 
Mulder CH, Cooke TJ. 2009. Family ties and residential locations. Population, Space and Place 15: 299-304. DOI:10.1002/psp.556.

Mulder CH, Hooimeijer P. 1999. Residential relocations in the life course. In Population Issues: An Interdisciplinary Focus, Van Wissen L, Dykstra P (eds.); Plenum Press: New York; 159-186.

Rabe B, Taylor M. 2010. Residential mobility, quality of neighbourhood and life course events. Journal of the Royal Statistical Society: Series A 173: 531-555.

DOI:10.1111/j.1467-985X.2009.00626.x.

Rossi PH. 1955. Why Families Move: A Study in the Social Psychology of Urban Residential Mobility. Glencoe: Free Press.

Seavers J. 1999. Residential relocation of couples: the joint decision-making process considered. In Migration and Gender in the Developed World, Boyle P Halfacree K (eds.); Routledge: London; 151-171.

Sell RG, De Jong G. 1983. Deciding whether to move: mobility, wishful thinking and adjustment. Sociology \& Social Research 67: 146-165.

Speare A, Goldstein S, Frey W. 1975. Residential Mobility, Migration, and Metropolitan Change. Ballinger Publishing: Cambridge.

Taylor MF with Brice J, Buck N, Prentice-Lane E. 2010. British Household Panel Survey User Manual Volume A: Introduction, Technical Report and Appendices. University of Essex: Colchester.

Van Ham M, Feijten P. 2008. Who wants to leave the neighbourhood? The effect of being different from the neighbourhood population on wishes to move. Environment and Planning A 40: 1151-1170. DOI: 10.1068/a39179. 
Table 1. Variable summary statistics (total $\mathrm{N}=30,617$ couple-years)

\begin{tabular}{|c|c|c|}
\hline Variable & $\mathbf{N}$ & $\%$ \\
\hline Mover couple dummy (ref=no move) & 2,160 & 7.05 \\
\hline \multicolumn{3}{|l|}{ Housing satisfaction (ref=both satisfied) } \\
\hline Man dissatisfied & 3,035 & 9.91 \\
\hline Woman dissatisfied & 3,691 & 12.06 \\
\hline Both dissatisfied & 2,834 & 9.26 \\
\hline \multicolumn{3}{|l|}{ Disliking the neighbourhood (ref=neither dislikes) } \\
\hline Man dislikes & 1,010 & 3.30 \\
\hline Woman dislikes & 1,084 & 3.54 \\
\hline Both dislike & 888 & 2.90 \\
\hline \multicolumn{3}{|l|}{ Moving desires (ref=neither desires to move) } \\
\hline Man desires & 3,051 & 9.97 \\
\hline Woman desires & 2,799 & 9.14 \\
\hline Both desire & 6,090 & 19.89 \\
\hline \multicolumn{3}{|l|}{ Moving expectations (ref=neither expect to move) } \\
\hline Man expects & 637 & 2.08 \\
\hline Woman expects & 698 & 2.28 \\
\hline Both expect & 2,064 & 6.74 \\
\hline Cohabitation dummy (ref=married) & 4,839 & 15.80 \\
\hline \multicolumn{3}{|l|}{ Couple type (ref=couple, no children) } \\
\hline Preschool children & 2,669 & 8.72 \\
\hline School age children & 7,844 & 25.62 \\
\hline Children of both ages & 1,966 & 6.42 \\
\hline Non-dependent children & 3,795 & 12.40 \\
\hline Other & 376 & 1.23 \\
\hline \multicolumn{3}{|l|}{ Change in $n$ kids $t$ to $t+1$ (ref $=$ no change $)$} \\
\hline Increase & 1,280 & 4.18 \\
\hline Decrease & 1,404 & 4.59 \\
\hline Unknown at $t+1$ & 830 & 2.71 \\
\hline \multicolumn{3}{|l|}{ Highest education level (ref=very low/none) } \\
\hline Low (basic secondary school level) & 5,900 & 19.27 \\
\hline Medium (higher school/vocational qualifications) & 15,184 & 49.59 \\
\hline High (degree and above) & 6,383 & 20.85 \\
\hline \multicolumn{3}{|l|}{ Employment status of the couple (ref=neither employed) } \\
\hline Dual earner & 16,851 & 55.04 \\
\hline Single earner & 6,995 & 22.85 \\
\hline \multicolumn{3}{|l|}{ Change in $n$ employed $t$ to $t+1$ (ref=no change) } \\
\hline Increase & 1,430 & 4.67 \\
\hline Decrease & 1,895 & 6.19 \\
\hline Unknown at $t+1$ & 1,383 & 4.52 \\
\hline \multicolumn{3}{|l|}{ Housing tenure (ref=homeowner) } \\
\hline Social renter & 3,890 & 12.71 \\
\hline Private renter & 1,741 & 5.69 \\
\hline \multicolumn{3}{|l|}{ Longest duration of stay in years $(\mathrm{ref}=0-1)$} \\
\hline $2-5$ & 6,008 & 19.62 \\
\hline $6-10$ & 3,348 & 10.94 \\
\hline $11-20$ & 4,030 & 13.16 \\
\hline $21-40$ & 3,011 & 9.83 \\
\hline$>40$ & 619 & 2.02 \\
\hline Unknown & 9,229 & 30.14 \\
\hline Continuous variables & Mean & Std. Dev. \\
\hline Highest age & 49.36 & 15.05 \\
\hline Real household income $(£) / 10,000$ & 3.42 & 2.45 \\
\hline Roomstress ( $n$ people/ $n$ rooms) & 0.67 & 0.30 \\
\hline
\end{tabular}


Figure 1. Partner (dis)agreement in moving desires by age

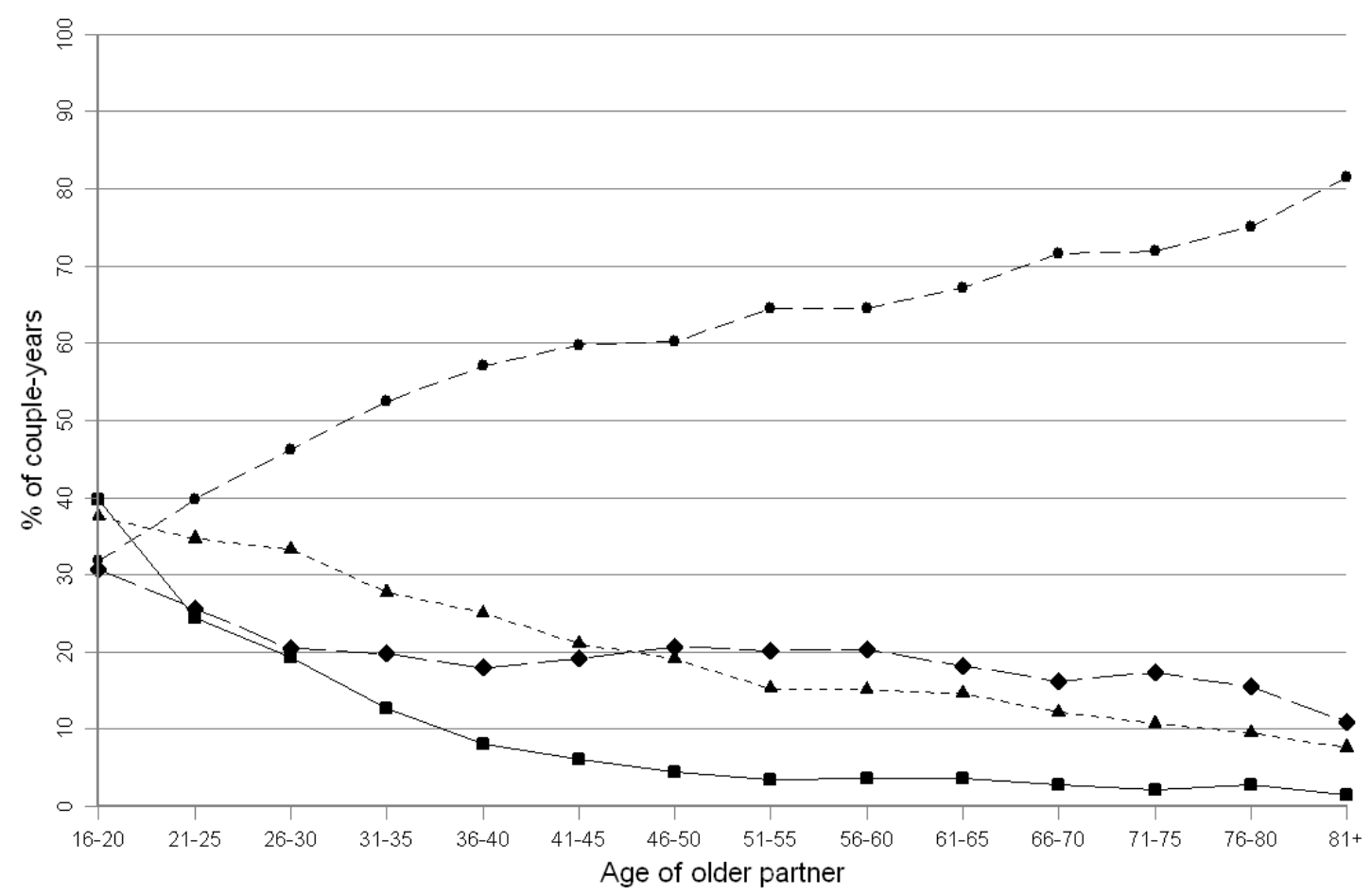

$--\bullet$ Neither desire $\longrightarrow \bullet-$ Disagree $-\ldots-\ldots$ Both desire $\longrightarrow-$ Actual mobility rate 
Table 2. Partner similarity and (dis)agreement on whether moving is desirable

\begin{tabular}{|c|c|c|c|c|c|}
\hline \multirow{2}{*}{\multicolumn{2}{|c|}{ Couple characteristic (row \%) }} & \multicolumn{3}{|c|}{ Moving desires of the couple } & \multirow{2}{*}{$\begin{array}{r}\text { Total (100\% and } n \\
\text { couple-years) }\end{array}$} \\
\hline & & Neither desires & Disagree & Both desire & \\
\hline \multirow[t]{5}{*}{ Age gap (years) } & $0-2$ & 62.40 & 18.94 & 18.66 & 14,360 \\
\hline & $3-5$ & 61.13 & 18.47 & 20.40 & 9,146 \\
\hline & $6-10$ & 57.82 & 20.63 & 21.55 & 5,225 \\
\hline & $11-20$ & 58.35 & 18.73 & 22.92 & 1,671 \\
\hline & $>21$ & 60.00 & 23.26 & 16.74 & 215 \\
\hline \multirow{5}{*}{$\begin{array}{l}\text { Education level } \\
\text { gap }\end{array}$} & No gap & 61.22 & 18.77 & 20.02 & 13,044 \\
\hline & Small gap & 61.57 & 18.63 & 19.80 & 12,314 \\
\hline & Large gap & 58.61 & 20.83 & 20.55 & 3,936 \\
\hline & Very large gap & 65.65 & 16.96 & 17.39 & 230 \\
\hline & Unknown & 59.65 & 22.78 & 17.57 & 1,093 \\
\hline \multirow{3}{*}{$\begin{array}{l}\text { Housing } \\
\text { satisfaction }\end{array}$} & Both satisfied & 72.76 & 16.61 & 10.62 & 21,057 \\
\hline & Disagree & 42.52 & 26.08 & 31.40 & 6,726 \\
\hline & Both dissatisfied & 17.47 & 21.10 & 61.43 & 2,834 \\
\hline \multirow{3}{*}{$\begin{array}{l}\text { Liking the } \\
\text { neighbourhood }\end{array}$} & Both like & 67.01 & 18.46 & 14.53 & 27,635 \\
\hline & Disagree & 7.35 & 34.43 & 58.21 & 2,094 \\
\hline & Both dislike & 0.68 & 3.04 & 96.28 & 888 \\
\hline \multicolumn{2}{|c|}{ Total $(100 \%$ and $n$ couple-years) } & & & & 30,617 \\
\hline
\end{tabular}

All bivariate associations have Pearson's $\mathrm{chi}^{2} p<0.01$

Source: BHPS (own calculations) 
Table 3. Shared commitments and (dis)agreement on whether moving is desirable

\begin{tabular}{|c|c|c|c|c|c|}
\hline \multicolumn{2}{|c|}{ Couple characteristic (row \%) } & \multicolumn{3}{|c|}{ Moving desires of the couple } & \multirow{2}{*}{$\begin{array}{r}\text { Total }(100 \% \text { and } n \\
\text { couple-years) }\end{array}$} \\
\hline & & Neither desires & Disagree & Both desire & \\
\hline \multirow[t]{2}{*}{ Marital status } & Married & 63.81 & 18.43 & 17.76 & 25,778 \\
\hline & Cohabiting & 46.06 & 22.71 & 31.23 & 4,839 \\
\hline \multirow{6}{*}{$\begin{array}{l}\text { Couple's } \\
\text { household type }\end{array}$} & Couple only & 64.36 & 18.10 & 17.54 & 13,967 \\
\hline & Preschool children & 52.12 & 18.70 & 29.19 & 2,669 \\
\hline & School age children & 59.54 & 19.31 & 21.15 & 7,844 \\
\hline & Children of both ages & 55.14 & 21.31 & 23.55 & 1,966 \\
\hline & Non-dependent children & 63.11 & 20.58 & 16.31 & 3,795 \\
\hline & Other & 39.36 & 28.72 & 31.91 & 376 \\
\hline \multirow[t]{4}{*}{ Housing tenure } & Homeowner & 63.91 & 18.55 & 17.54 & 24,986 \\
\hline & Social renter & 48.51 & 21.59 & 29.90 & 3,890 \\
\hline & Private renter & 47.16 & 21.54 & 31.30 & 1,741 \\
\hline & & \multicolumn{3}{|c|}{ Total $(100 \%$ and $n$ couple-years) } & 30,617 \\
\hline
\end{tabular}

All bivariate associations have Pearson's chi ${ }^{2} p<0.01$

Source: BHPS (own calculations) 
Table 4. Moving desires and the subsequent moving behaviour of couples

\begin{tabular}{|c|c|c|c|c|}
\hline \multicolumn{2}{|c|}{ Moving desires at $t$} & \multicolumn{3}{|c|}{ Subsequent couple moving behaviour $t$ to $t+1$} \\
\hline & & Stayer & Mover & Total $(100 \%$ and $n)$ \\
\hline \multirow{3}{*}{$\begin{array}{l}\text { Individual } \\
\text { level } \\
\text { analysis }\end{array}$} & No male desire & 96.71 & 3.29 & 21,476 \\
\hline & Male desire & 84.10 & 15.90 & 9,141 \\
\hline & Total & 28,457 & 2,160 & 30,617 \\
\hline \multirow{5}{*}{$\begin{array}{l}\text { Couple } \\
\text { level } \\
\text { analysis }\end{array}$} & Neither desires & 97.29 & 2.71 & 18,677 \\
\hline & Man desires & 92.43 & 7.57 & 3,051 \\
\hline & Woman desires & 92.82 & 7.18 & 2,799 \\
\hline & Both desire & 79.93 & 20.07 & 6,090 \\
\hline & Total & 28,457 & 2,160 & 30,617 \\
\hline
\end{tabular}

All bivariate associations have Pearson's $\mathrm{chi}^{2} p<0.01$

Source: BHPS (own calculations) 
Table 5. Panel logistic regression models of the annual moving propensity of couples between $t$ and $t+1$

\begin{tabular}{|c|c|c|c|c|c|c|c|c|c|c|}
\hline \multirow[t]{2}{*}{ Variable (observed at wave $t$ ) } & \multicolumn{2}{|c|}{ Model 1} & \multicolumn{2}{|c|}{ Model 2} & \multicolumn{2}{|c|}{ Model 3} & \multicolumn{2}{|c|}{ Model 4} & \multicolumn{2}{|c|}{ Model 5} \\
\hline & Coeff. & S.E. & Coeff. & S.E. & Coeff. & S.E. & Coeff. & S.E. & Coeff. & S.E. \\
\hline \multicolumn{11}{|c|}{ Housing satisfaction (ref=both satisfied) } \\
\hline Man dissatisfied & $0.977 * * *$ & 0.081 & $0.690 * * *$ & 0.079 & & & & & $0.226 * *$ & 0.092 \\
\hline Woman dissatisfied & $1.033 * * *$ & 0.074 & $0.790 * * *$ & 0.073 & & & & & $0.308 * * *$ & 0.085 \\
\hline Both dissatisfied & $1.751 * * *$ & 0.078 & $1.100 * * *$ & 0.077 & & & & & 0.130 & 0.091 \\
\hline \multicolumn{11}{|c|}{ Dislike neighbourhood (ref=both like) } \\
\hline Man dislikes & $0.460 * * *$ & 0.120 & $0.410 * * *$ & 0.117 & & & & & -0.122 & 0.135 \\
\hline Woman dislikes & $0.649 * * *$ & 0.111 & $0.620 * * *$ & 0.106 & & & & & 0.068 & 0.124 \\
\hline Both dislike & $0.953 * * *$ & 0.115 & $0.968 * * *$ & 0.109 & & & & & -0.081 & 0.127 \\
\hline \multicolumn{11}{|l|}{ Desire to move (ref=neither desire) } \\
\hline Man desires & & & & & $0.756 * * *$ & 0.098 & $0.646^{* * *}$ & 0.098 & $0.629 * * *$ & 0.100 \\
\hline Woman desires & & & & & $0.475 * * *$ & 0.104 & $0.386^{* * *}$ & 0.105 & $0.322 * *$ & 0.108 \\
\hline Both desire & & & & & $0.969 * * *$ & 0.077 & $0.879 * * *$ & 0.077 & $0.825 * * *$ & 0.083 \\
\hline \multicolumn{11}{|c|}{ Expect to move (ref=neither expect) } \\
\hline Man expects & & & & & $1.817 * * *$ & 0.125 & $1.417 * * *$ & 0.127 & $1.414 * * *$ & 0.128 \\
\hline Woman expects & & & & & $2.120 * * *$ & 0.115 & $1.738 * * *$ & 0.116 & $1.720 * * *$ & 0.117 \\
\hline Both expect & & & & & $3.735 * * *$ & 0.085 & $3.200 * * *$ & 0.084 & $3.197 * * *$ & 0.084 \\
\hline Highest age & & & $-0.033 * * *$ & 0.003 & & & $-0.024 * * *$ & 0.003 & $-0.024 * * *$ & 0.003 \\
\hline Cohabit $($ ref $=$ married $)$ & & & -0.022 & 0.067 & & & $-0.179 * *$ & 0.078 & $-0.181 * *$ & 0.078 \\
\hline \multicolumn{11}{|c|}{ Couple type (ref=couple, no children) } \\
\hline Preschool chldren & & & $-0.231 * *$ & 0.084 & & & -0.111 & 0.099 & -0.121 & 0.099 \\
\hline School age children & & & $-0.753 * * *$ & 0.081 & & & $-0.499 * * *$ & 0.091 & $-0.513 * * *$ & 0.091 \\
\hline Children of both ages & & & $-0.657 * * *$ & 0.110 & & & $-0.261 * *$ & 0.125 & $-0.266 * *$ & 0.125 \\
\hline Non-dependent children & & & $-0.634 * * *$ & 0.115 & & & $-0.360 * *$ & 0.125 & $-0.361 * *$ & 0.125 \\
\hline Other & & & $0.336 * *$ & 0.169 & & & -0.146 & 0.201 & -0.158 & 0.202 \\
\hline \multicolumn{11}{|c|}{ Change in $n$ children (ref $=$ no change) } \\
\hline Increased at $t+1$ & & & 0.170 & 0.096 & & & -0.046 & 0.114 & -0.049 & 0.115 \\
\hline Decreased at $t+1$ & & & -0.080 & 0.143 & & & 0.010 & 0.162 & 0.009 & 0.162 \\
\hline Unknown at $t+1$ & & & $2.075 * * *$ & 0.204 & & & $1.975^{* * *}$ & 0.231 & $1.987 * * *$ & 0.231 \\
\hline \multicolumn{11}{|c|}{ Highest education level (ref=very low) } \\
\hline Low & & & 0.206 & 0.122 & & & 0.089 & 0.132 & 0.085 & 0.132 \\
\hline Medium & & & 0.131 & 0.117 & & & -0.088 & 0.126 & -0.098 & 0.126 \\
\hline High & & & $0.378 * *$ & 0.128 & & & -0.081 & 0.140 & -0.090 & 0.140 \\
\hline
\end{tabular}




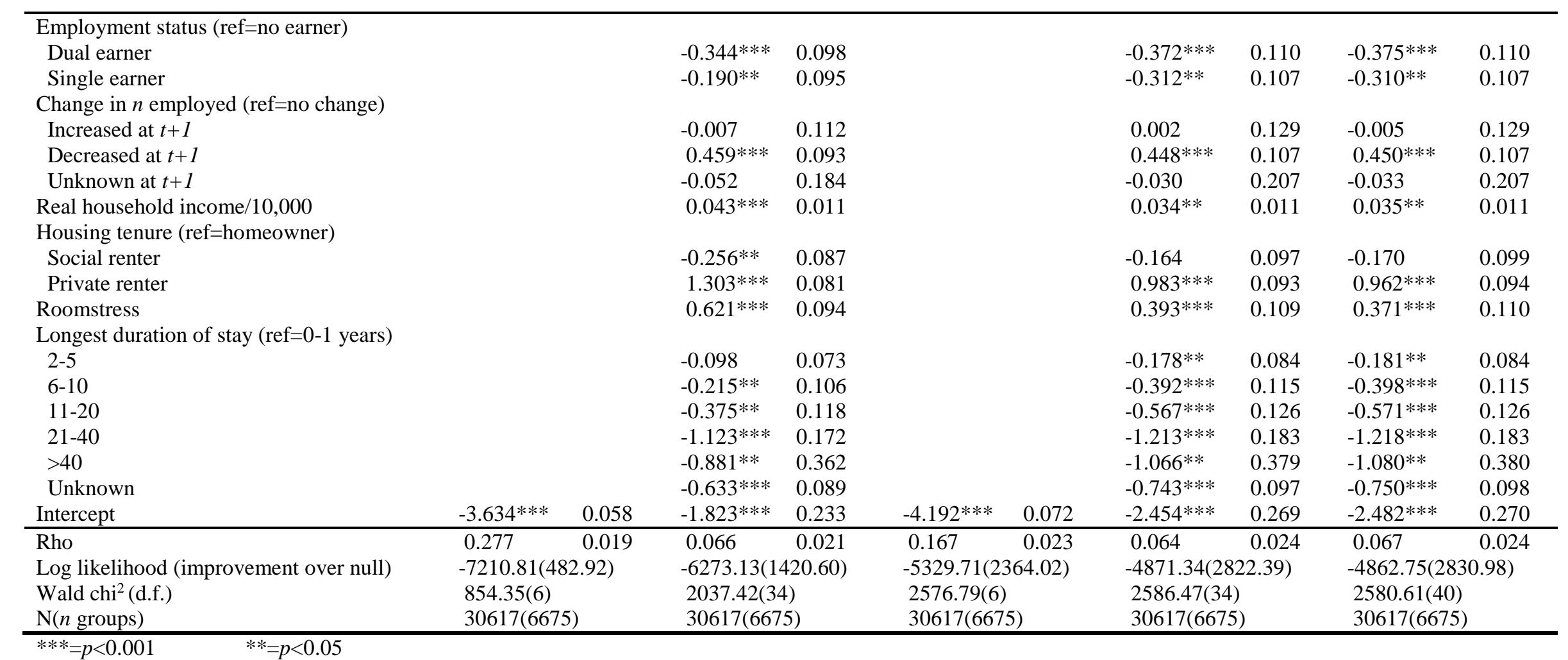

Source: BHPS (own calculations) 